\title{
Growth patterns from birth to 24 months in Chinese children: a birth cohorts study across China
}

Fengxiu Ouyang ${ }^{1 *}$, Fan Jiang ${ }^{1,2}$, Fangbiao Tao ${ }^{3}$, Shunqing Xu ${ }^{4}$, Yankai Xia ${ }^{5}$, Xiu Qiu ${ }^{6}$ and Jun Zhang ${ }^{1 *}$

\begin{abstract}
Background: Assessment of child growth is important in detecting under- and over-growth. We aimed to examine the growth patterns of healthy Chinese infants from birth to 24 months.

Methods: This study was based on six recent birth cohorts across China, which provided data (from 2015) on 4251 children (2174 boys, 2077 girls) who were born at term to mothers without gestational or preexisting diabetes, chronic hypertension, preeclampsia, or eclampsia. Analyses were performed using 28,298 longitudinal anthropometric measures in 4251 children and the LMS method to generate smoothed Z-score growth curves, which were compared to the WHO growth standards (which are based on data from 2003) and current Chinese growth references (which are based on data from 2005).

Results: Most (80.3\%) of mother had college education or more, and maternal smoking was rare (0.4\%). Compared to the WHO longitudinal growth standards for children aged 0 to 2 years, the growth references from this longitudinal study (length-, weight-, head circumference-, BMI-for-age, and weight-for-length) were significantly higher, for boys and girls; Specifically, the median length-, weight-, head circumference-, BMl-for-age, and weightfor-length was on average 0.9 (range $0.2-1.3$ ) $\mathrm{cm}, 0.51$ (range 0.09-0.74) kg, 0.17 (range -0.24 to 0.37 ) $\mathrm{cm}, 0.70$ (range 0.01 to 0.92 ) kg/m², and 0.43 (range 0.01 to 1.07 ) $\mathrm{kg}$ higher in Chinese boys, and 1.3 (range $0.5-1.9$ ) $\mathrm{cm}, 0.73$ (range $0.10-0.91$ ) kg, 0.45 (range $0.15-0.62$ ) $\mathrm{cm}, 0.7$ (range 0.0 to 1.0 ) kg/ $\mathrm{m}^{2}$, and 0.42 (range 0.00 to 0.64 ) $\mathrm{kg}$ greater in Chinese girls, respectively. Compared to the current China cross-sectional growth references (based on data from a decade ago), growth references from this study were also higher, but the difference was less than that between growth references of this study and WHO growth standards.

Conclusions: This recent multicenter prospective birth cohort study examined early growth patterns in China. The new growth curves represent the growth patterns of healthy Chinese infants evaluated longitudinally from 0 to 24 months of age, and provide references for monitoring growth in early life in modern China that are more recent than WHO longitudinal growth standards from other countries and previous cross-sectional growth references for China.
\end{abstract}

Keywords: Growth standards, Chinese children, Infancy

\footnotetext{
* Correspondence: ouyangfengxiu@xinhuamed.com.cn;

ouyangfengxiu@126.com; junjimzhang@sina.com

${ }^{1}$ Ministry of Education and Shanghai Key Laboratory of Children's

Environmental Health, Xinhua Hospital, Shanghai Jiao Tong University School

of Medicine, 1665 Kong Jiang Road, Shanghai 200092, China

Full list of author information is available at the end of the article
}

(c) The Author(s). 2018 Open Access This article is distributed under the terms of the Creative Commons Attribution 4.0 International License (http://creativecommons.org/licenses/by/4.0/), which permits unrestricted use, distribution, and reproduction in any medium, provided you give appropriate credit to the original author(s) and the source, provide a link to the Creative Commons license, and indicate if changes were made. The Creative Commons Public Domain Dedication waiver (http://creativecommons.org/publicdomain/zero/1.0/) applies to the data made available in this article, unless otherwise stated. 


\section{Background}

The assessment of child growth is important in detecting under- and over-growth, which can provide information for timely intervention. The first 1000 days of life (from conception to 2 years of age) is a period of rapid growth and development, and vulnerable to nutritional and environmental influences [1]. Identifying normal child growth patterns is of fundamental importance in growth assessment.

Both the World Health Organization (WHO) growth standards [2] and the China growth references [3] are being applied in China. The WHO growth standards for children aged 0 to 24 months were constructed based on longitudinal data of children $(n=882)$ by using selection criteria of having socioeconomic conditions favorable to growth and having access to breastfeeding support (for qualifying as "standard") from the WHO Multicenter Growth Reference Study (MGRS) conducted in six countries from 1997 to 2003 (without a site in China). The China growth charts were constructed from a large $(n=44,250)$ cross-sectional study based on stratified random sampling of children in nine cities of China, which was conducted from May to October in 2005 [3]. Comparison of the growth curves over the restricted range of ages from 0 to 2 years indicated the reference for China was significant higher for BMI for boys and girls. However, the comparisons were complicated by differences in inclusion/exclusion criteria (for the WHO sample, strict criteria about known constraints on growth and cooperation with feeding recommendations, which led to over $80 \%$ of mother-infant pairs being ineligible; for the China sample, multistage stratified cluster sampling was used based on urban/suburban areas, districts, and community, with several exclusion criteria), as well as by differences in the design of the studies (longitudinal for the WHO study and cross-sectional for the study in China). The difference between China growth references and WHO growth standards could have been an artifact, so confirmation study is warranted.

Historically, in some circumstances, secular trends of height have occurred from one generation to the next generation [4]. China has a diverse population, environment, dietary habits and tradition, and it is going through rapid modernization and urbanization. Early child growth has drawn much attention since these factors may affect growth. China started the 1st National Survey on the Physical Growth and Development of Children (NSPGDC) in the nine cities of China in 1975, and conducted the survey every 10 years from 1975 to 2005 to address possible secular trends, with the most recent data (from 2005) providing the current references for growth in China [3] (but in need of a 10-year update in 2015). Longitudinal data from a sample with stricter inclusion/exclusion criteria would provide a better comparison to the WHO standards. A small cohort [5] recruited in 2007 ( $n=1531$ retained up to 1 year of age) with strict WHO criteria applied showed significant differences (heavier in weight, longer in length, and bigger in head circumference) compared to WHO standards, as well as compared to the current cross-sectional references, which showed similar differences (except for the 97th percentiles that were lower rather than higher).

Long-term follow-up data has enormous value in evaluating the optimal individual growth trajectory, which may not be captured by cross-sectional data [3, 6]. Between 2012 and 2014, six longitudinal birth cohort studies were launched in China. A number of common exposures shared by all cohorts were collected and common outcomes were observed, which formed the foundation of China Birth Cohort Consortium (CBCC). This collaboration provided, for the first time in China, longitudinal growth data from birth cohorts from various regions of the country, but it still is a convenience sample from an efficient combination of cohorts.

This report examines growth patterns from birth to 24 months in Chinese children by pooling the individual level anthropometric follow-up measures from CBCC. The growth references from the $2015 \mathrm{CBCC}$ will be used for comparison to the $2006 \mathrm{WHO}$ longitudinal growth standards and the 2005 China cross-sectional growth references to provide an update on how healthy infants are growing in modern China.

\section{Methods}

\section{Study population and data collection}

This study used data from six birth cohorts of CBCC which were located at Shanghai (2 cohorts), Anhui, Guangdong, Hubei, and Jiangsu Provinces and were initiated between 2012 and 2014 (Additional file 1: Table S1_1 and S1_2). Additional file 1: Table S1_2 presents the study objective of each of the 6 cohorts. The original aims of these prospective cohorts were to study the environmental, genetic and behavioral factors during pregnancy and in early childhood, and their effects on pregnancy outcomes, fetal and child growth and development, and risks of diseases. Pregnant women were recruited at hospitals when they came for their routine prenatal care visits.

Weight, length, head circumference, and gestational age at birth were obtained from obstetrical medical records. Child anthropometric measurements including weight, length, and head circumference were conducted by trained study staff or trained pediatric nurses in maternal and child health care centers according to the WHO protocol at 7 targeted ages (42 days, 3, 6, 9, 12, 18 and 24 months; http:// www.who.int/childgrowth/training/en/). Recumbent length on infants was measured with infant head position in the Frankfort Vertical Plane, and the soles of the feet flat on the moveable footboard. The cohort staffs were trained by 
group-watching WHO training video course on weight, length, and head circumference. The pediatric nurse measurements were made as routine care was provided. Infant age was calculated by date at measurement minus date of birth. Feeding type in the first 6 months was classified into three types: exclusive breastfeeding, mixed feeding (i.e., combination of breastfeeding and formula feeding), and exclusive/only formula feeding [7]. Infant passive smoking exposure was defined by the mother or father smoking, or for anyone else living in the home smoking. The diagnosis of gestational diabetes mellitus (GDM) in pregnant women was based on the recommendations of International Association of Diabetes and Pregnancy Study Groups (IADPSG) [8].

For this project, we requested each of the six birth cohort studies to contribute longitudinal child growth data of 1000 singleton children from birth to 2 years of age, or maximum number available at the time of our data request in July, 2016. Two cohorts contributed child follow-up measurements up to 12 months due to later starting date (2014) or child follow-up schedule (Additional file 1: Table S1). The inclusion criteria included singleton live births. The exclusion criteria included: (1) infants born with congenital malformations; (2) pregnancy conceived by assisted reproductive technologies (ART); (3) women with medical complication of sexually transmitted diseases (syphilis, HIV infection, and AIDS); (4) women with pre-existed diabetes. There were 5152 mother-child pairs, which provided a sample almost 6 times greater than the WHO longitudinal cohort from 2003 and over 3 times greater than the previous China longitudinal cohort from 2007. While birth cohort studies used better trained personnel for the growth assessments, more observations can also offset "imprecise observations".

Among the 5152 mothers, 672 had GDM, 213 had preterm deliveries (gestational age $<37$ weeks), and 71 had hypertensive disorders in pregnancy. Among the remaining 4258, 7 had missing data on infant sex. To generate the growth references, we used data from 4251 normal term-born children and excluded children of mothers with GDM, hypertensive disorders in pregnancy (e.g., chronic hypertension, gestational hypertension, preeclampsia and eclampsia),children born preterm to avoid the potential influences of known prenatal risk factors [10-12],and children with missing data on sex.

\section{Statistical analysis}

We used the LMS method to fit smooth z-score curves for length, weight, head circumference and BMI according to age, and for weight according to length respectively in normal term-born healthy children, stratified by infant sex. [13] The three curves of median (M), coefficient of variation (S) and skewness (L, which is expressed as a Box-Cox power) across age/or length were fitted as cubic splines by using maximum penalized likelihood [13]. The z-score of child growth measures y (length, weight, head circumference and BMI) at time $t$ (or length $t$, for weight-for-length) was calculated from the smooth curve $\mathrm{L}(\mathrm{t}), \mathrm{M}(\mathrm{t})$, and $\mathrm{S}(\mathrm{t})$ by the formula:

$$
\begin{aligned}
z & =\frac{[y / M(t)]^{L(t)}-1}{L(t) S(t)}, \text { if } L(\mathrm{t}) \neq 0 ; \quad z \\
& =\frac{\log [y / M(\mathrm{t})]}{S(\mathrm{t})}, \text { if } L(\mathrm{t})=0
\end{aligned}
$$

By using the maximum penalized likelihood and LMS method, all available data of infants from birth to 27 months, including those followed up to 12 months were able to be used to estimate the smoothing parameters and generate the smoothed curves $[9,13]$. The age-based references were truncated at 24 completed months to avoid the right-edge effect [14]. We compared z-scores of $0, \pm 2$, and \pm 3 for the growth measures in this study with the WHO standards (http://www.who.int/childgrowth/standards/en/), and the China 2005 references for children aged 0 to 2 years [3], both of which were constructed using similar LMS methods for smoothing procedures $[3,14]$. The two-sided $\mathrm{t}$-test was used to test statistical significance of the difference at a $p<0.05$. The growth curves were constructed by using LMSchartmaker Pro version 2.54 software (Medical Research Council, UK).

We also calculated the 3rd, 10th, 50th, 90th and 97th percentiles of all growth measures in both boys and girls by age with subgroup sample size $>100$ observations to summarize our data (without using smoothing technique), and compared these percentiles with WHO standards to show the differences. The analyses were conducted by using SAS 9.4 software (SAS Institute, Cary, North Carolina).

\section{Results}

This report presented the z-score curves of 4251 children who were born at term to mothers without gestational or preexisting diabetes, chronic hypertension, preeclampsia, or eclampsia. A total of 28,298 anthropometric measures were obtained from ages 0 to 27 months (Additional file 1: Tables S2 and S3). All were urban children. $51.1 \%$ were boys and $54.0 \%$ were delivered via $\mathrm{C}$-section. The mean maternal and paternal height was 161.4 (SD 4.9) $\mathrm{cm}$ and 174.4 (SD 5.3) $\mathrm{cm}$, respectively. Mean (pre-pregnancy) BMI was 20.6 (SD 2.8) $\mathrm{kg} / \mathrm{m}^{2}$ for mothers and 23.9 (SD 3.3) $\mathrm{kg} / \mathrm{m}^{2}$ for fathers. As expected, boy infants had greater birthweight, length and head circumference than girl infants (Table 1). Most (80.3\%) of mother had college education or more and 98.3\% of mother were Han ethnicity. During the first 6 months, most (77.6\%) of infants were mixed fed, and $13.4 \%$ had exclusive breast-feeding. In the first 2 years, 
Table 1 Characteristics of 4251 mothers, fathers and children by child sex

\begin{tabular}{|c|c|c|c|}
\hline & \multicolumn{2}{|l|}{ Infant sex } & \multirow{2}{*}{$\begin{array}{l}p \\
\text { value }\end{array}$} \\
\hline & Boy & Girl & \\
\hline Sample size & 2174 & 2077 & \\
\hline \multicolumn{4}{|l|}{ Maternal factors } \\
\hline Maternal age (years) & $28.7 \pm 3.4$ & $28.6 \pm 3.5$ & 0.51 \\
\hline Pre-pregnancy weight (kg) & $53.8 \pm 7.8$ & $53.7 \pm 8.1$ & 0.92 \\
\hline Maternal height (cm) & $161.3 \pm 4.9$ & $161.4 \pm 5.0$ & 0.33 \\
\hline Prepregnancy BMI $\left(\mathrm{kg} / \mathrm{m}^{2}\right)$ & $20.7 \pm 2.8$ & $20.6 \pm 2.8$ & 0.46 \\
\hline \multicolumn{4}{|l|}{ Mother Education } \\
\hline Junior high school or lower & $136(6.3)$ & 135(6.6) & 0.90 \\
\hline High school & $287(13.4)$ & $266(13.0)$ & \\
\hline College or above & $1725(80.3)$ & $1641(80.4)$ & \\
\hline \multicolumn{4}{|l|}{ Mother smoke during pregnancy } \\
\hline Yes & $10(0.5)$ & $7(0.3)$ & 0.53 \\
\hline No & 2148(99.5) & 2047(99.7) & \\
\hline \multicolumn{4}{|l|}{ Parity } \\
\hline Primiparous & 1958(90.2) & 1885(90.9) & 0.44 \\
\hline parous & 212(9.8) & 188(9.1) & \\
\hline \multicolumn{4}{|l|}{ Mode of Delivery } \\
\hline Vaginal delivery & $994(45.8)$ & $957(46.2)$ & 0.79 \\
\hline C-section & $1177(54.2)$ & 1115(53.8) & \\
\hline \multicolumn{4}{|l|}{ Paternal factors } \\
\hline Father age (years) & $30.6 \pm 4.4$ & $30.6 \pm 4.6$ & 0.69 \\
\hline Father height $(\mathrm{cm})$ & $174.2 \pm 5.2$ & $174.6 \pm 5.3$ & 0.04 \\
\hline Father weight (kg) & $72.5 \pm 11.2$ & $73.1 \pm 11.7$ & 0.14 \\
\hline Father BMI $\left(\mathrm{kg} / \mathrm{m}^{2}\right)$ & $23.9 \pm 3.2$ & $23.9 \pm 3.3$ & 0.56 \\
\hline \multicolumn{4}{|c|}{ Father smoke during mother pregnancy } \\
\hline Yes & $568(32.1)$ & $567(34.0)$ & 0.25 \\
\hline No & 1199(67.9) & $1101(66.0)$ & \\
\hline \multicolumn{4}{|l|}{ Infant factors } \\
\hline Birth weight (g) & $3399 \pm 404$ & $3309 \pm 392$ & $<0.001$ \\
\hline Birth length $(\mathrm{cm})$ & $50.2 \pm 1.4$ & $49.8 \pm 1.3$ & $<0.001$ \\
\hline Birth head circumference $(\mathrm{cm})$ & $34.1 \pm 1.1$ & $34.0 \pm 1.0$ & 0.01 \\
\hline Gestational age (weeks) & $39.1 \pm 1.0$ & $39.3 \pm 1.0$ & $<0.001$ \\
\hline \multicolumn{4}{|l|}{ Breastfeeding Type (0-6 months) } \\
\hline Formula feeding & 168(8.7) & $172(9.4)$ & 0.36 \\
\hline Exclusive Breastfeeding & 252(13.0) & $252(13.7)$ & \\
\hline Mixed feeding & 1518(78.3) & 1412(76.9) & \\
\hline \multicolumn{4}{|l|}{ Children passive smoking } \\
\hline No & $1187(72.7)$ & $1125(71.5)$ & 0.44 \\
\hline Yes & $445(27.3)$ & $448(28.5)$ & \\
\hline
\end{tabular}

Data were presented as mean $\pm \mathrm{SD}$, and $n(\%)$

$\mathrm{X}^{2}$ test for categorical variables and $\mathrm{t}$-test for continuous variables
27.9\% of children were exposed to passive-smoking. There was no sex difference for these factors (Table 1). Over the follow-up assessments (see Fig. 1), the children aged 0 to 2 years in this cohort were taller, heavier, and had greater head circumference than the children in the WHO cohort.

\section{Length-for-age}

Table 2 presents the growth references of length-for-age at $0, \pm 1, \pm 2$, and \pm 3 SD in our study. In comparison with the corresponding WHO growth standard from 0 to 24 months of age, the median length-for-age was on average $0.9 \mathrm{~cm}$ (range $0.2-1.3 \mathrm{~cm}$ ) higher in Chinese boys, and $1.3 \mathrm{~cm}$ (range 0.5-1.9 cm) higher in Chinese girls (Fig. 1). Similarly, for z-score of -2 (i.e. the cutoffs for defining stunting), child length was on average $1.1 \mathrm{~cm}$ taller (range 0.8$1.8 \mathrm{~cm}$ ) in Chinese boys and 1.6 (range 1.1-2.0) $\mathrm{cm}$ taller in Chinese girls than the corresponding sex-specific WHO curves. Likewise, for $\mathrm{z}$-score of -3 was higher in Chinese boys and girls across age.

Compared to the China growth reference (2005 data), the median length-for-age in our study (2015 data) was on average $0.3 \mathrm{~cm}$ higher in boys, and $0.5 \mathrm{~cm}$ higher in girls across age (Fig. 2). This might be evidence of a small secular trend. The comparisons to the 2005 China references were more similar than that for the comparisons to the WHO standards (Figs. 1 and 2).

\section{Weight-for-age}

Table 3 presents the growth reference of weight-for-age at 0 , $\pm 1, \pm 2$, and \pm 3 SD in our study. For weight-for-age z-score of -2 (cutoff point for defining underweight), weight was on average 0.60 (range 0.13-0.94) $\mathrm{kg}$ heavier in Chinese boys and 0.80 (range 0.19-1.10) $\mathrm{kg}$ heavier in Chinese girls than those of WHO standards across age (Fig. 1).

Compared to China reference from 2005 data, the weight-for-age median in our study (China 2015 data) was on average $0.25 \mathrm{~kg}$ higher (range $0.07-0.33 \mathrm{~kg}$ ) in boys, and $0.34 \mathrm{~kg}$ higher (range $0.09-0.42 \mathrm{~kg}$ ) in girls across age (Fig. 2).

\section{Head circumference-for-age}

Table 4 presents the growth reference of head circumference-for-age at $0, \pm 1, \pm 2$, and \pm 3 SD in our study. At the $\mathrm{z}$-score of -2 , head circumference was $0.36 \mathrm{~cm}$ greater (range 0.08 to $0.86 \mathrm{~cm}$ ) in Chinese boys, and $0.76 \mathrm{~cm}$ greater (range 0.54 to $1.04 \mathrm{~cm}$ ) in Chinese girls, than the corresponding WHO standards (Fig. 1).

Compared to cross-sectional 2005 norms for China, the median head circumference-for-age in our study was similar in boys, but on average $0.3 \mathrm{~cm}$ greater (range $0.1-0.7 \mathrm{~cm}$ ) in girls across age (Fig. 2). 


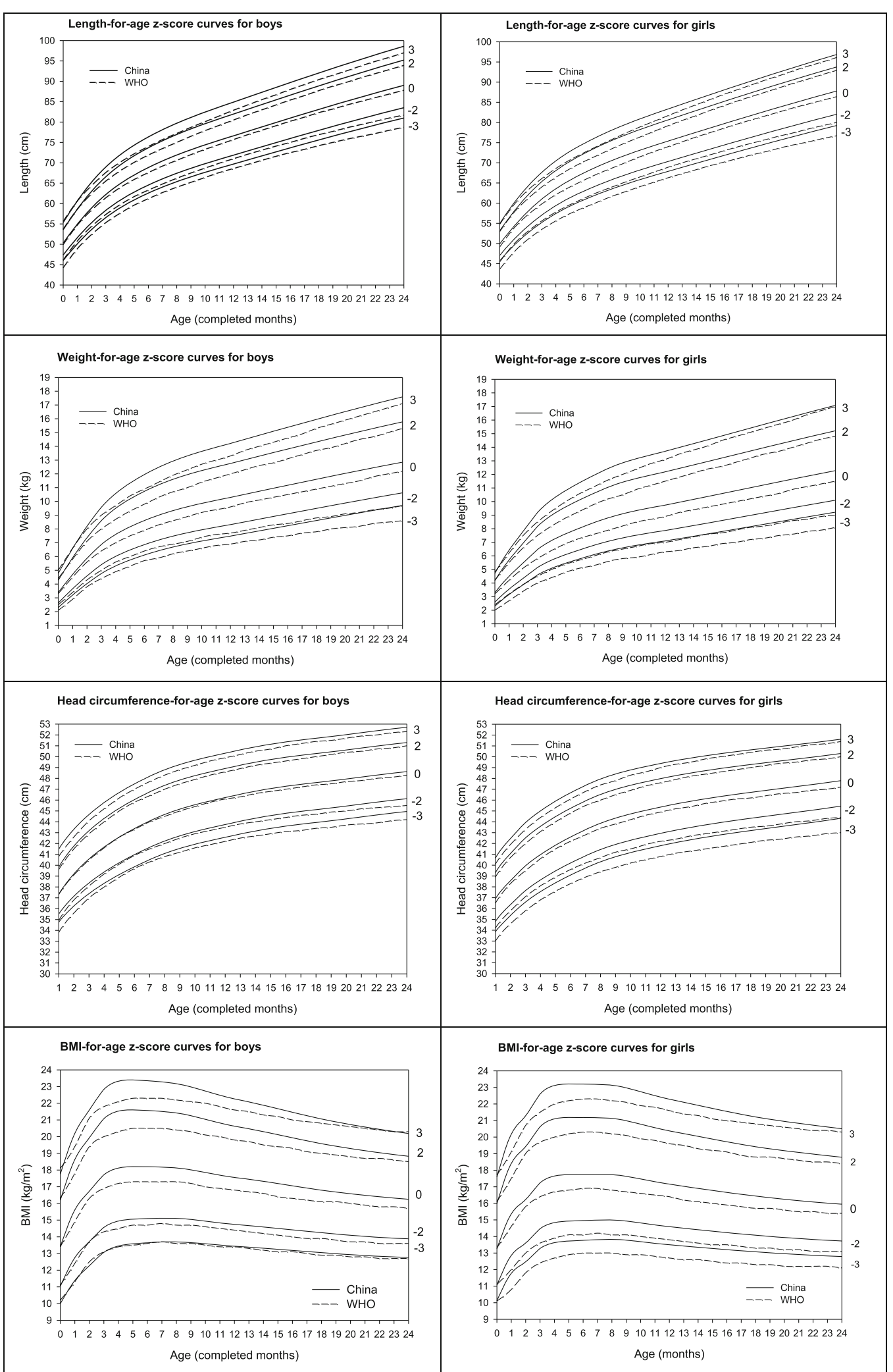

Fig. 1 Comparison of growth-for-age z-score curves with WHO standards in boys and girls 
Table 2 Length (cm)-for-age $z$-score curves at 0, $\pm 1, \pm 2$, and \pm 3 SD for Chinese boys and girls from birth to 24 months

\begin{tabular}{|c|c|c|c|c|c|c|c|c|c|c|c|c|c|c|c|c|c|c|c|c|}
\hline \multirow{2}{*}{$\begin{array}{l}\text { Age } \\
\text { (month) }\end{array}$} & \multicolumn{10}{|l|}{ Boys } & \multicolumn{10}{|l|}{ Girls } \\
\hline & L & M & S & $-3 S D$ & $-2 S D$ & $-1 S D$ & OSD & $1 S D$ & $2 S D$ & $3 S D$ & $\mathrm{~L}$ & M & $S$ & $-3 S D$ & $-2 S D$ & $-1 S D$ & OSD & $1 S D$ & $2 S D$ & $3 S D$ \\
\hline 0 & -0.7996 & 50.3 & 0.0306 & 46.0 & 47.4 & 48.8 & 50.3 & 51.9 & 53.6 & 55.3 & -1.0973 & 49.9 & 0.0305 & 45.7 & 47.0 & 48.4 & 49.9 & 51.5 & 53.2 & 55.0 \\
\hline 1 & -0.7996 & 54.9 & 0.0318 & 50.1 & 51.6 & 53.2 & 54.9 & 56.7 & 58.6 & 60.6 & -0.9519 & 54.2 & 0.0320 & 49.4 & 50.9 & 52.5 & 54.2 & 55.9 & 57.9 & 59.9 \\
\hline 2 & -0.7996 & 58.9 & 0.0326 & 53.6 & 55.3 & 57.1 & 58.9 & 60.9 & 63.0 & 65.3 & -0.6922 & 57.9 & 0.0331 & 52.6 & 54.3 & 56.0 & 57.9 & 59.9 & 62.0 & 64.2 \\
\hline 2 & -0.7996 & 62.2 & 0.0330 & 56.6 & 58.3 & 60.2 & 62.2 & 64.3 & 66.6 & 69.0 & -0.3981 & 61.0 & 0.0338 & 55.3 & 57.1 & 59.0 & 61.0 & 63.2 & 65.4 & 67.7 \\
\hline & -0.7996 & 64.8 & 0.0331 & 58.9 & 60.8 & 62.8 & 64.8 & 67.1 & 69.4 & 71.9 & -0.1356 & 63.6 & 0.0342 & 57.4 & 59.4 & 61.4 & 63.6 & 65.8 & 68.1 & 70.5 \\
\hline 5 & -0.7996 & 67.0 & 0.0332 & 60.9 & 62.8 & 64.8 & 67.0 & 69.3 & 71.7 & 74.3 & 0.0640 & 65.7 & 0.0343 & 59.2 & 61.3 & 63.5 & 65.7 & 68.0 & 70.3 & 72.8 \\
\hline 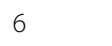 & -0.7996 & 68.8 & 0.0331 & 62.6 & 64.5 & 66.6 & 68.8 & 71.2 & 73.7 & 76.3 & 0.2052 & 67.5 & 0.0344 & 60.8 & 63.0 & 65.2 & 67.5 & 69.9 & 72.3 & 74.8 \\
\hline 7 & -0.7996 & 70.5 & 0.0330 & 64.0 & 66.1 & 68.2 & 70.5 & 72.9 & 75.4 & 78.1 & 0.2974 & 69.1 & 0.0344 & 62.2 & 64.5 & 66.8 & 69.1 & 71.5 & 74.0 & 76.5 \\
\hline 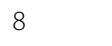 & -0.7996 & 71.9 & 0.0330 & 65.4 & 67.4 & 69.6 & 71.9 & 74.4 & 76.9 & 79.7 & 0.3533 & 70.6 & 0.0344 & 63.5 & 65.8 & 68.2 & 70.6 & 73.0 & 75.6 & 78.1 \\
\hline & -0.7996 & 73.2 & 0.0329 & 66.6 & 68.7 & 70.9 & 73.2 & 75.7 & 78.3 & 81.1 & 0.3867 & 71.9 & 0.0344 & 64.7 & 67.1 & 69.5 & 71.9 & 74.4 & 77.0 & 79.6 \\
\hline 10 & -0.7996 & 74.4 & 0.0329 & 67.7 & 69.8 & 72.0 & 74.4 & 76.9 & 79.6 & 82.5 & 0.4064 & 73.1 & 0.0343 & 65.8 & 68.2 & 70.7 & 73.1 & 75.7 & 78.3 & 80.9 \\
\hline 11 & -0.7996 & 75.5 & 0.0328 & 68.7 & 70.8 & 73.1 & 75.5 & 78.1 & 80.8 & 83.7 & 0.4167 & 74.3 & 0.0342 & 66.9 & 69.3 & 71.8 & 74.3 & 76.9 & 79.5 & 82.1 \\
\hline 12 & -0.7996 & 76.6 & 0.0328 & 69.7 & 71.9 & 74.2 & 76.6 & 79.2 & 82.0 & 84.9 & & 75.4 & 0.0342 & 67.9 & 70.3 & 72.8 & 75.4 & 78.0 & 80.6 & 83.3 \\
\hline 13 & -0.7996 & 77.7 & 0.0328 & 70.7 & 72.9 & 75.2 & 77.7 & 80.3 & 83.1 & 86.1 & 0.4205 & 76.5 & 0.0341 & 68.9 & 71.4 & 73.9 & 76.5 & 79.1 & 81.8 & 84.5 \\
\hline 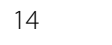 & -0.7996 & 78.8 & 0.0328 & 71.7 & 73.9 & 76.3 & 78.8 & 81.5 & 84.3 & 87.3 & 0.4189 & 77.6 & 0.0341 & 69.9 & 72.4 & 74.9 & 77.6 & 80.2 & 82.9 & 85.7 \\
\hline 15 & -0.7996 & 79.9 & 0.0327 & 72.7 & 74.9 & 77.3 & 79.9 & 82.6 & 85.4 & 88.5 & 0.4166 & 78.6 & 0.0340 & 70.9 & 73.4 & 76.0 & 78.6 & 81.3 & 84.1 & 86.9 \\
\hline 16 & -0.7996 & 81.0 & 0.0327 & 73.7 & 76.0 & 78.4 & 81.0 & 83.7 & 86.6 & 89.7 & 0.4142 & 79.7 & 0.0339 & 71.8 & 74.4 & 77.0 & 79.7 & 82.5 & 85.2 & 88.1 \\
\hline 17 & -0.7996 & 82.1 & 0.0327 & 74.7 & 77.0 & 79.4 & 82.1 & 84.8 & 87.8 & 90.9 & 0.4125 & 80.8 & 0.0339 & 72.8 & 75.4 & 78.1 & 80.8 & 83.6 & 86.4 & 89.2 \\
\hline 18 & -0.7996 & 83.1 & 0.0327 & 75.6 & 78.0 & 80.5 & 83.1 & 85.9 & 88.9 & 92.1 & 0.4121 & 81.8 & 0.0338 & 73.8 & 76.4 & 79.1 & 81.8 & 84.6 & 87.5 & 90.4 \\
\hline 19 & -0.7996 & 84.1 & 0.0327 & 76.6 & 78.9 & 81.5 & 84.1 & 87.0 & 90.0 & 93.2 & 0.4134 & 82.9 & 0.0337 & 74.7 & 77.4 & 80.1 & 82.9 & 85.7 & 88.6 & 91.5 \\
\hline 20 & -0.7996 & 85.2 & 0.0327 & 77.5 & 79.9 & 82.4 & 85.2 & 88.0 & 91.1 & 94.3 & 0.4154 & 83.9 & 0.0336 & 75.7 & 78.3 & 81.1 & 83.9 & 86.7 & 89.6 & 92.6 \\
\hline 21 & -0.7996 & 86.1 & 0.0327 & 78.4 & 80.8 & 83.4 & 86.1 & 89.0 & 92.1 & 95.4 & 0.4169 & 84.9 & 0.0336 & 76.6 & 79.3 & 82.0 & 84.9 & 87.7 & 90.7 & 93.7 \\
\hline 22 & -0.7996 & 87.1 & 0.0327 & 79.3 & 81.7 & 84.3 & 87.1 & 90.0 & 93.2 & 96.5 & 0.4172 & 85.8 & 0.0335 & 77.5 & 80.2 & 83.0 & 85.8 & 88.8 & 91.7 & 94.7 \\
\hline 23 & -0.7996 & 88.1 & 0.0327 & 80.1 & 82.6 & 85.3 & 88.1 & 91.0 & 94.2 & 97.5 & 0.4164 & 86.8 & 0.0335 & 78.4 & 81.1 & 83.9 & 86.8 & 89.8 & 92.7 & 95.8 \\
\hline 24 & -0.7996 & 89.0 & 0.0327 & 81.0 & 83.5 & 86.2 & 89.0 & 92.0 & 95.2 & 98.6 & 0.4146 & 87.8 & 0.0334 & 79.2 & 82.0 & 84.9 & 87.8 & 90.7 & 93.8 & 96.8 \\
\hline
\end{tabular}

\section{BMI-for-age}

Table 5 presents the growth reference of BMI-for-age at 0 , $\pm 1, \pm 2$, and \pm 3 SD in our study. As shown in Fig. 1 , median BMI-for-age was on average $0.70 \mathrm{~kg} / \mathrm{m}^{2}$ (range 0.01 to $0.92 \mathrm{~kg} / \mathrm{m}^{2}$ ) higher in Chinese boys, and 0.7 (range 0.0 to 1.0$) \mathrm{kg} / \mathrm{m}^{2}$ higher in Chinese girls than the corresponding WHO standards across the age of 0-24 months. For z-score of 2 , BMI on average $\sim 0.70 \mathrm{~kg} / \mathrm{m}^{2}$ higher in Chinese boys and girls than the WHO standards.

Compared to the China corresponding growth references from 2005 data, the median BMI-for-age in our study was on average $0.3 \mathrm{~kg} / \mathrm{m}^{2}$ higher in boys and $0.4 \mathrm{~kg} / \mathrm{m}^{2}$ higher in girls across age (Fig. 2).

\section{Weight-for-length}

Table 6 presents the growth references of weight-for-length at $0, \pm 1, \pm 2$, and $\pm 3 \mathrm{SD}$ in our study. Median weight-for-length was on average $0.43 \mathrm{~kg}$ greater (range 0.01 to $1.07 \mathrm{~kg}$ ) than WHO standards in boys, and $0.42 \mathrm{~kg}$ greater (range 0.00 to $0.64 \mathrm{~kg}$ ) in Chinese girls from body length $\geq 50 \mathrm{~cm}$ (Fig. 3), but lighter weight at the very short length in Chinese girls $(<52 \mathrm{~cm})$.

For z-score of - 2 (cutoff for wasting definition) in boys, weight was $\sim 0.29 \mathrm{~kg}$ higher (range $0.003-0.94 \mathrm{~kg}$ ) than the WHO standard at length $\geq 64 \mathrm{~cm}$; between length $45-63 \mathrm{~cm}$, it was $0.08 \mathrm{~kg}$ lower (ranged 0.02 to -0.17 ) (Fig. 3). In Chinese girls, the weight-for-length values at z-score of -2 were on average $0.44 \mathrm{~kg}$ heavier (ranging 0.001 to $0.85 \mathrm{~kg}$ ) than the WHO standards for length $\geq 49 \mathrm{~cm}$. For z-score of 2 (cutoff for overweight definition), compared to the WHO standards, weight was on average $0.39 \mathrm{~kg}$ higher (range 0.04 to $0.75 \mathrm{~kg}$ ) in Chinese boys, and $0.34 \mathrm{~kg}$ higher (range 0.06 to $0.64 \mathrm{~kg}$ ) in Chinese girls for the length $\geq 50 \mathrm{~cm}$. Similarly, for z-score of 3 , weight-for-length was on average $0.16 \mathrm{~kg}$ higher (range - 0.11to $0.36 \mathrm{~kg}$ ) in Chinese boys, and was $0.30 \mathrm{~kg}$ higher (range 0.00 to $0.64 \mathrm{~kg}$ ) at most length $(49 \mathrm{~cm}$ to $95 \mathrm{~cm}$ ) in Chinese girls than the WHO standards.

Compared to cross-sectional 2005 growth references for China, the median weight-for-length was on average 


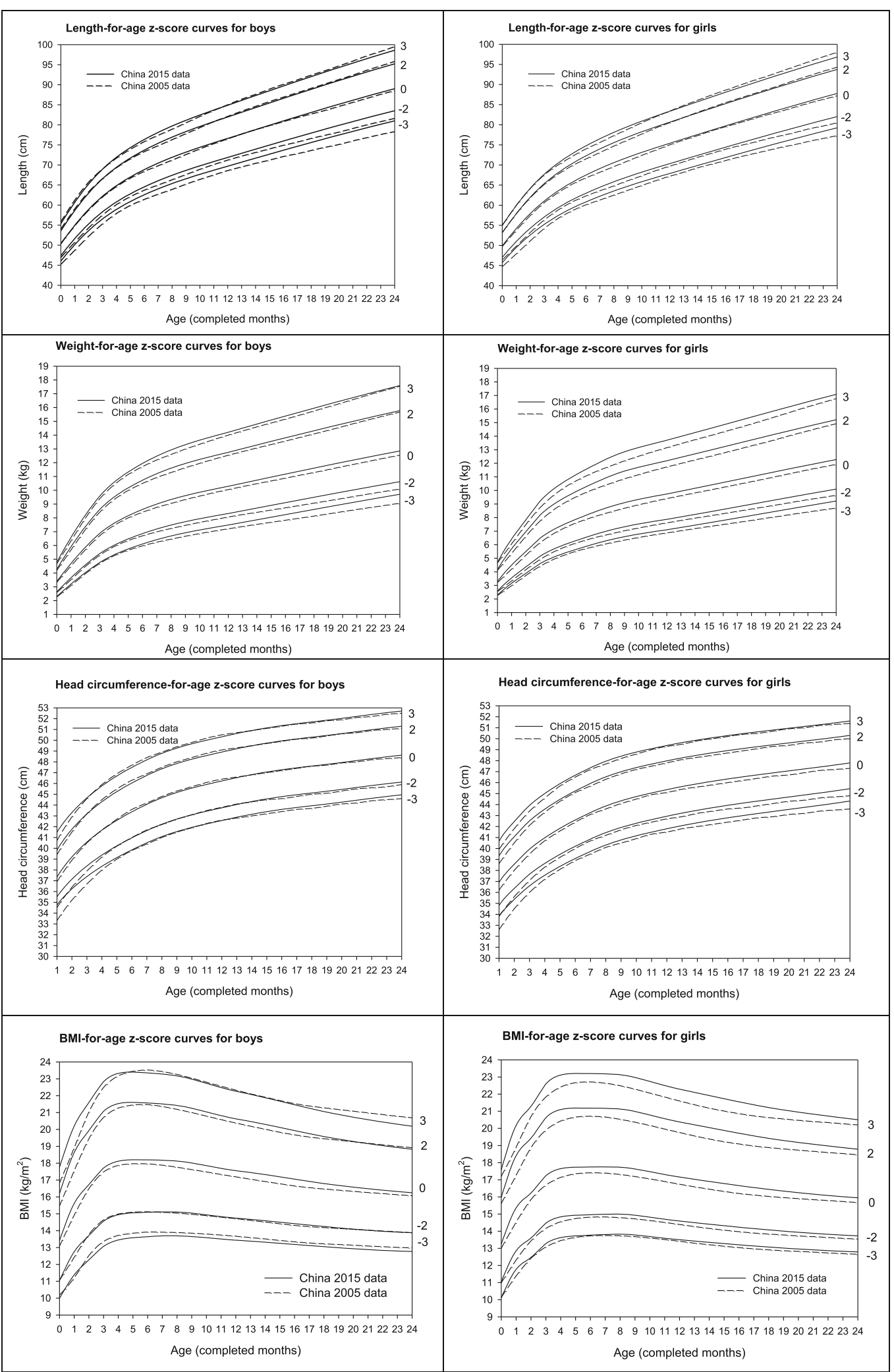

Fig. 2 Comparison of growth-for-age z-score curves from China 2015 data (the present study) with those from China 2005 data in boys and girls 


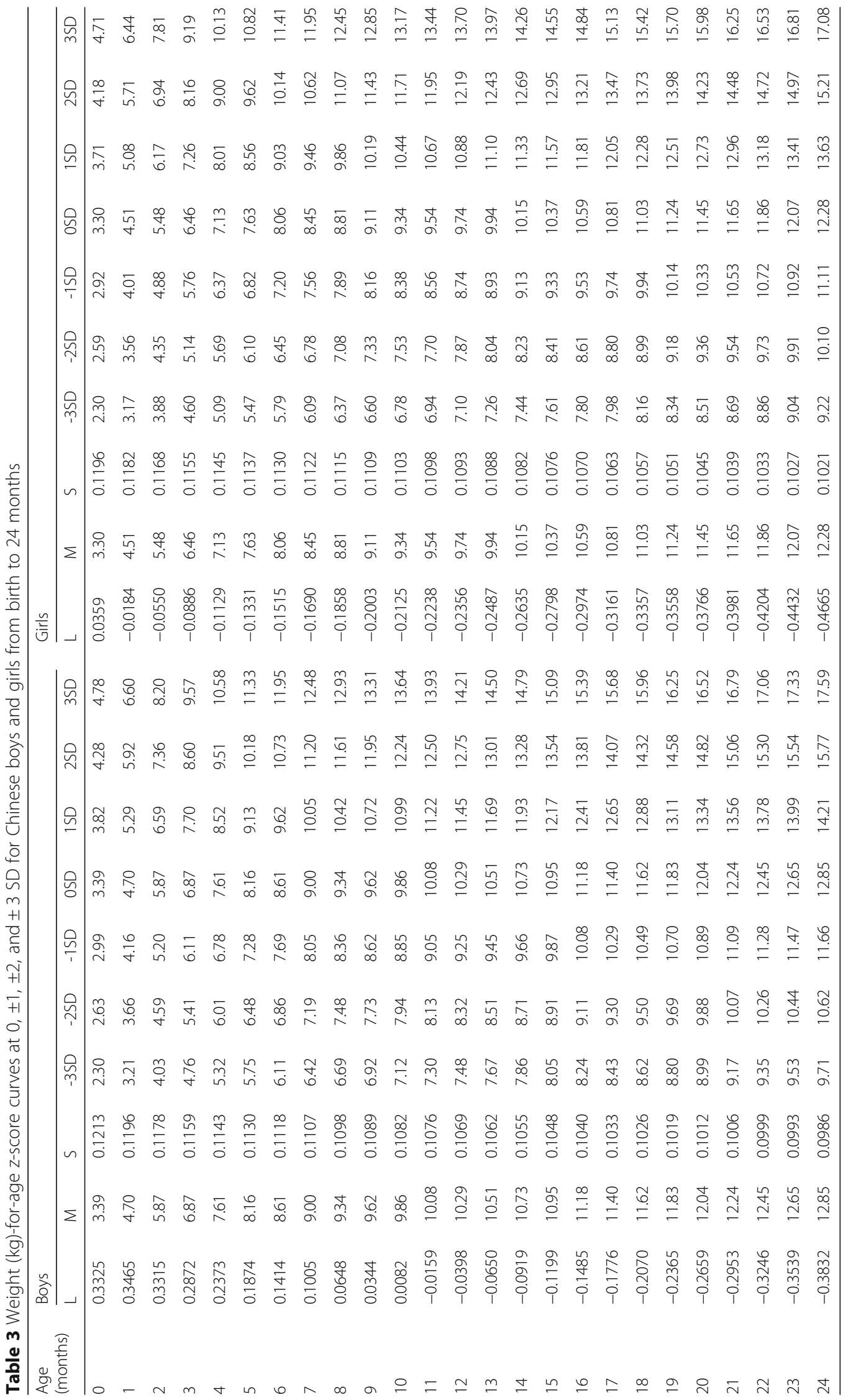


Table 4 Head circumference (cm)-for-age z-score curves at 0, $\pm 1, \pm 2$, and \pm 3 SD for Chinese boys and girls from birth to 24 months

\begin{tabular}{|c|c|c|c|c|c|c|c|c|c|c|c|c|c|c|c|c|c|c|c|c|}
\hline \multirow{2}{*}{$\begin{array}{l}\text { Age } \\
\text { (months) }\end{array}$} & \multicolumn{10}{|l|}{ Boys } & \multicolumn{10}{|l|}{ Girls } \\
\hline & L & M & $S$ & $-3 S D$ & $-2 S D$ & $-1 S D$ & OSD & $1 S D$ & $2 S D$ & $3 S D$ & L & $M$ & S & $-3 S D$ & $-2 S D$ & $-1 S D$ & OSD & $1 S D$ & $2 S D$ & $3 \mathrm{SD}$ \\
\hline 0 & -7.0263 & 34.3 & 0.0262 & 32.2 & 32.8 & 33.4 & 34.3 & 35.3 & 36.6 & 38.4 & -1.4337 & 34.1 & 0.0300 & 31.3 & 32.1 & 33.1 & 34.1 & 35.1 & 36.3 & 37.5 \\
\hline 1 & -4.4686 & 37.3 & 0.0280 & 34.8 & 35.5 & 36.4 & 37.3 & 38.5 & 39.8 & 41.5 & -1.2431 & 36.9 & 0.0304 & 33.9 & 34.8 & 35.8 & 36.9 & 38.1 & 39.3 & 40.7 \\
\hline 2 & -2.7515 & 39.2 & 0.0291 & 36.3 & 37.1 & 38.1 & 39.2 & 40.4 & 41.8 & 43.3 & -1.0791 & 38.6 & 0.0304 & 35.4 & 36.4 & 37.4 & 38.6 & 39.8 & 41.1 & 42.5 \\
\hline 3 & -1.7763 & 40.6 & 0.0294 & 37.4 & 38.4 & 39.5 & 40.6 & 41.8 & 43.2 & 44.7 & -0.9472 & 40.0 & 0.0303 & 36.6 & 37.7 & 38.8 & 40.0 & 41.2 & 42.5 & 43.9 \\
\hline 4 & -1.2600 & 41.7 & 0.0295 & 38.3 & 39.4 & 40.5 & 41.7 & 43.0 & 44.3 & 45.8 & -0.8444 & 41.0 & 0.0301 & 37.6 & 38.6 & 39.8 & 41.0 & 42.2 & 43.6 & 45.0 \\
\hline 5 & -0.9752 & 42.6 & 0.0293 & 39.2 & 40.2 & 41.4 & 42.6 & 43.9 & 45.3 & 46.7 & -0.7629 & 41.8 & 0.0298 & 38.4 & 39.5 & 40.6 & 41.8 & 43.1 & 44.5 & 45.9 \\
\hline 6 & -0.7968 & 43.4 & 0.0291 & 39.9 & 41.0 & 42.1 & 43.4 & 44.7 & 46.0 & 47.5 & -0.6960 & 42.6 & 0.0295 & 39.1 & 40.2 & 41.4 & 42.6 & 43.9 & 45.2 & 46.7 \\
\hline 7 & -0.6658 & 44.1 & 0.0289 & 40.5 & 41.6 & 42.8 & 44.1 & 45.4 & 46.7 & 48.2 & -0.6377 & 43.3 & 0.0292 & 39.7 & 40.9 & 42.0 & 43.3 & 44.6 & 45.9 & 47.4 \\
\hline 8 & -0.5616 & 44.7 & 0.0286 & 41.1 & 42.2 & 43.4 & 44.7 & 46.0 & 47.4 & 48.8 & -0.5863 & 43.9 & 0.0289 & 40.3 & 41.5 & 42.6 & 43.9 & 45.2 & 46.5 & 48.0 \\
\hline 9 & -0.4796 & 45.2 & 0.0284 & 41.6 & 42.7 & 43.9 & 45.2 & 46.5 & 47.9 & 49.3 & -0.5444 & 44.3 & 0.0286 & 40.8 & 41.9 & 43.1 & 44.3 & 45.6 & 47.0 & 48.4 \\
\hline 10 & -0.4171 & 45.6 & 0.0282 & 41.9 & 43.1 & 44.3 & 45.6 & 46.9 & 48.2 & 49.7 & -0.5097 & 44.7 & 0.0283 & 41.2 & 42.3 & 43.5 & 44.7 & 46.0 & 47.4 & 48.8 \\
\hline 11 & -0.3699 & 45.9 & 0.0280 & 42.3 & 43.4 & 44.7 & 45.9 & 47.2 & 48.6 & 50.0 & -0.4793 & 45.1 & 0.0280 & 41.5 & 42.6 & 43.8 & 45.1 & 46.3 & 47.7 & 49.1 \\
\hline 12 & -0.3349 & 46.2 & 0.0278 & 42.6 & 43.8 & 45.0 & 46.2 & 47.5 & 48.9 & 50.3 & -0.4516 & 45.4 & 0.0278 & 41.8 & 42.9 & 44.1 & 45.4 & 46.6 & 48.0 & 49.4 \\
\hline 13 & -0.3116 & 46.5 & 0.0277 & 42.9 & 44.1 & 45.3 & 46.5 & 47.8 & 49.2 & 50.6 & -0.4262 & 45.6 & 0.0275 & 42.1 & 43.2 & 44.4 & 45.6 & 46.9 & 48.3 & 49.6 \\
\hline 14 & -0.3002 & 46.8 & 0.0275 & 43.2 & 44.3 & 45.6 & 46.8 & 48.1 & 49.5 & 50.9 & -0.4029 & 45.9 & 0.0273 & 42.3 & 43.5 & 44.7 & 45.9 & 47.2 & 48.5 & 49.9 \\
\hline 15 & -0.2977 & 47.1 & 0.0274 & 43.4 & 44.6 & 45.8 & 47.1 & 48.4 & 49.7 & 51.1 & -0.3819 & 46.1 & 0.0271 & 42.6 & 43.7 & 44.9 & 46.1 & 47.4 & 48.7 & 50.1 \\
\hline 16 & -0.2997 & 47.3 & 0.0273 & 43.6 & 44.8 & 46.0 & 47.3 & 48.6 & 49.9 & 51.4 & -0.3629 & 46.3 & 0.0269 & 42.8 & 43.9 & 45.1 & 46.3 & 47.6 & 48.9 & 50.3 \\
\hline 17 & -0.3039 & 47.4 & 0.0272 & 43.8 & 45.0 & 46.2 & 47.4 & 48.8 & 50.1 & 51.5 & -0.3456 & 46.5 & 0.0267 & 43.0 & 44.1 & 45.3 & 46.5 & 47.8 & 49.1 & 50.5 \\
\hline 18 & -0.3091 & 47.6 & 0.0271 & 43.9 & 45.1 & 46.3 & 47.6 & 48.9 & 50.3 & 51.7 & -0.3293 & 46.7 & 0.0265 & 43.2 & 44.3 & 45.5 & 46.7 & 48.0 & 49.3 & 50.6 \\
\hline 19 & -0.3155 & 47.8 & 0.0270 & 44.1 & 45.3 & 46.5 & 47.8 & 49.1 & 50.4 & 51.9 & -0.3135 & 46.9 & 0.0263 & 43.4 & 44.5 & 45.7 & 46.9 & 48.1 & 49.4 & 50.8 \\
\hline 20 & -0.3232 & 47.9 & 0.0269 & 44.3 & 45.5 & 46.7 & 47.9 & 49.3 & 50.6 & 52.0 & -0.2976 & 47.1 & 0.0261 & 43.6 & 44.7 & 45.9 & 47.1 & 48.3 & 49.6 & 50.9 \\
\hline 21 & -0.3320 & 48.1 & 0.0268 & 44.5 & 45.6 & 46.9 & 48.1 & 49.4 & 50.8 & 52.2 & -0.2811 & 47.2 & 0.0260 & 43.7 & 44.9 & 46.0 & 47.2 & 48.5 & 49.8 & 51.1 \\
\hline 22 & -0.3414 & 48.3 & 0.0267 & 44.6 & 45.8 & 47.0 & 48.3 & 49.6 & 51.0 & 52.4 & -0.2641 & 47.4 & 0.0258 & 43.9 & 45.1 & 46.2 & 47.4 & 48.7 & 50.0 & 51.3 \\
\hline 23 & -0.3506 & 48.5 & 0.0266 & 44.8 & 46.0 & 47.2 & 48.5 & 49.8 & 51.1 & 52.6 & -0.2473 & 47.6 & 0.0256 & 44.1 & 45.3 & 46.4 & 47.6 & 48.9 & 50.1 & 51.5 \\
\hline 24 & -0.3592 & 48.6 & 0.0265 & 45.0 & 46.1 & 47.4 & 48.6 & 49.9 & 51.3 & 52.7 & -0.2313 & 47.8 & 0.0254 & 44.3 & 45.4 & 46.6 & 47.8 & 49.0 & 50.3 & 51.6 \\
\hline
\end{tabular}

$0.31 \mathrm{~kg}-\mathrm{cm}$ higher (range $0.03-1.00 \mathrm{~kg}-\mathrm{cm}$ ) in boys and 0.28 (range $0.02-0.56) \mathrm{kg}-\mathrm{cm}$ higher in girls across length in this study (Fig. 3).

The difference between our raw data and WHO standards The numbers of anthropometric measurements used for generating smoothed growth curves was shown in Additional file 1: Tables S2 and S3. This study measured the children at 7 targeted ages (42 days, 3, 6, 9, 12, 18 and 24 months), but in fact provided adequate monthly numbers in the first 12 months (Additional file 1: Tables S2 and S3). In addition to above comparison of the LMS-method-fitted smoothing curves, we also presented the 3rd, 10th, 50th, 90th and 97th percentiles of growth measures by age in both boys (Additional file 1: Table S4) and girls (Additional file 1: Table S5). Compared to the corresponding $2006 \mathrm{WHO}$ percentile standards, the 3rd, 10th, 50th, 90th and 97th percentiles (across the ages evaluated in this study from 0 to 2 years) for length, weight, and BMI (Additional file 1: Table S4 for boys and
Additional file 1: Table S5 for girls) were consistently higher in healthy Chinese boys (Additional file 1: Table S6) and girls (Additional file 1: Table S7) in 2015. For example, the median lengths from 0 to 2 years were 50.0 $89.5 \mathrm{~cm}$ in boys (Additional file 1: Table S4), which were $0.1-3.1 \mathrm{~cm}$ taller than the WHO percentile standards (Additional file 1: Table S6). The differences compared to WHO standards also were present for weight by length in both boys and girls (Additional file 1: Tables S8 and S9). This indicates the robust of our results.

\section{Discussion}

This report of growth measures is based on a large cohort of children $(n=4251)$ from six recent birth cohorts from China. Growth references from this study represent normal growth of today's Chinese children from birth to 24 months by using the multicenter data collected recently (from 2012 to 2015). Compared with the WHO standards (collected more than 10 years ago from mid-1997 to end of 2003) and the current China 
Table 5 BMl-for-age $z$-score at $0, \pm 1, \pm 2$, and \pm 3 SD for Chinese boys and girls from birth to 24 months

\begin{tabular}{|c|c|c|c|c|c|c|c|c|c|c|c|c|c|c|c|c|c|c|c|c|}
\hline \multirow{2}{*}{$\begin{array}{l}\text { Age } \\
\text { (month) }\end{array}$} & \multicolumn{10}{|l|}{ Boys } & \multicolumn{10}{|l|}{ Girls } \\
\hline & L & M & S & $-3 S D$ & $-2 S D$ & $-1 S D$ & OSD & $1 S D$ & $2 S D$ & $3 S D$ & L & M & $S$ & $-3 S D$ & $-2 S D$ & $-1 S D$ & OSD & $1 S D$ & $2 S D$ & $3 S D$ \\
\hline 0 & 0.1590 & 13.4 & 0.0958 & 10.0 & 11.0 & 12.2 & 13.4 & 14.7 & 16.2 & 17.8 & -0.1727 & 13.3 & 0.0920 & 10.1 & 11.1 & 12.1 & 13.3 & 14.5 & 16.0 & 17.6 \\
\hline 1 & 0.7178 & 15.6 & 0.0943 & 11.4 & 12.8 & 14.2 & 15.6 & 17.1 & 18.6 & 20.2 & -0.0900 & 15.4 & 0.0898 & 11.8 & 12.9 & 14.1 & 15.4 & 16.8 & 18.4 & 20.2 \\
\hline 2 & 0.6937 & 16.7 & 0.0930 & 12.3 & 13.7 & 15.2 & 16.7 & 18.3 & 19.9 & 21.6 & -0.1078 & 16.2 & 0.0891 & 12.5 & 13.6 & 14.8 & 16.2 & 17.7 & 19.4 & 21.3 \\
\hline 3 & 0.6483 & 17.7 & 0.0920 & 13.1 & 14.6 & 16.1 & 17.7 & 19.4 & 21.1 & 22.8 & -0.1322 & 17.2 & 0.0886 & 13.3 & 14.5 & 15.8 & 17.2 & 18.8 & 20.6 & 22.6 \\
\hline & 0.6054 & 18.1 & 0.0909 & 13.5 & 14.9 & 16.5 & 18.1 & 19.8 & 21.5 & 23.3 & -0.1567 & 17.7 & 0.0880 & 13.6 & 14.8 & 16.2 & 17.7 & 19.3 & 21.1 & 23.1 \\
\hline 5 & 0.5683 & 18.2 & 0.0899 & 13.6 & 15.1 & 16.6 & 18.2 & 19.9 & 21.6 & 23.4 & -0.1810 & 17.7 & 0.0875 & 13.7 & 14.9 & 16.3 & 17.7 & 19.4 & 21.2 & 23.2 \\
\hline & 0.5384 & 18.2 & 0.0890 & 13.6 & 15.1 & 16.6 & 18.2 & 19.8 & 21.6 & 23.4 & -0.2055 & 17.7 & 0.0869 & 13.8 & 15.0 & 16.3 & 17.7 & 19.4 & 21.2 & 23.2 \\
\hline 7 & 0.5161 & 18.2 & 0.0880 & 13.7 & 15.1 & 16.6 & 18.2 & 19.8 & 21.5 & 23.3 & -0.2298 & 17.8 & 0.0863 & 13.8 & 15.0 & 16.3 & 17.8 & 19.4 & 21.2 & 23.2 \\
\hline & 0.5000 & 18.1 & 0.0871 & 13.7 & 15.1 & 16.6 & 18.1 & 19.7 & 21.4 & 23.2 & -0.2535 & 17.7 & 0.0857 & 13.8 & 15.0 & 16.3 & 17.7 & 19.3 & 21.1 & 23.1 \\
\hline & 0.4888 & 18.0 & 0.0862 & 13.7 & 15.0 & 16.5 & 18.0 & 19.6 & 21.3 & 23.0 & -0.2763 & 17.6 & 0.0851 & 13.8 & 14.9 & 16.2 & 17.6 & 19.2 & 21.0 & 23.0 \\
\hline 10 & 0.4814 & 17.9 & 0.0854 & 13.6 & 14.9 & 16.4 & 17.9 & 19.4 & 21.0 & 22.7 & -0.2981 & 17.5 & 0.0845 & 13.7 & 14.8 & 16.1 & 17.5 & 19.0 & 20.8 & 22.7 \\
\hline 1 & 4767 & 17.7 & 0.0846 & 13.5 & 14.8 & 16.2 & 17.7 & 19.2 & 20.8 & 22.5 & -0.3192 & 17.3 & 0.0839 & 13.6 & 14.7 & 15.9 & 17.3 & 18.8 & 20.6 & 22.5 \\
\hline 17) & 0.4735 & 17.6 & 0.0838 & 13.4 & 14.7 & 16.1 & 17.6 & 19.1 & 20.6 & 22.3 & -0.3398 & 17.2 & 0.0834 & 13.5 & 14.6 & 15.8 & 17.2 & 18.7 & 20.4 & 22.3 \\
\hline 13 & 0.4713 & 17.4 & 0.0830 & 13.4 & 14.7 & 16.0 & 17.4 & 18.9 & 20.5 & 22.1 & -0.3598 & 17.0 & 0.0828 & 13.4 & 14.5 & 15.7 & 17.0 & 18.5 & 20.2 & 22.1 \\
\hline 14 & 0.4693 & 17.3 & 0.0823 & 13.3 & 14.6 & 15.9 & 17.3 & 18.8 & 20.3 & 21.9 & -0.3794 & 16.9 & 0.0823 & 13.4 & 14.4 & 15.6 & 16.9 & 18.4 & 20.0 & 21.9 \\
\hline 15 & 0.4673 & 17.2 & 0.0816 & 13.3 & 14.5 & 15.8 & 17.2 & 18.6 & 20.1 & 21.7 & -0.3984 & 16.8 & 0.0818 & 13.3 & 14.3 & 15.5 & 16.8 & 18.2 & 19.9 & 21.7 \\
\hline 16 & 0.4654 & 17.1 & 0.0809 & 13.2 & 14.4 & 15.7 & 17.1 & 18.5 & 19.9 & 21.5 & -0.4169 & 16.7 & 0.0814 & 13.2 & 14.2 & 15.4 & 16.7 & 18.1 & 19.7 & 21.5 \\
\hline 17 & 0.4635 & 16.9 & 0.0802 & 13.1 & 14.3 & 15.6 & 16.9 & 18.3 & 19.7 & 21.3 & -0.4349 & 16.5 & 0.0809 & 13.1 & 14.1 & 15.3 & 16.5 & 18.0 & 19.6 & 21.4 \\
\hline 18 & 0.4616 & 16.8 & 0.0795 & 13.0 & 14.2 & 15.5 & 16.8 & 18.2 & 19.6 & 21.1 & -0.4524 & 16.4 & 0.0805 & 13.1 & 14.1 & 15.2 & 16.4 & 17.8 & 19.4 & 21.2 \\
\hline 19 & 0.4598 & 16.7 & 0.0789 & 13.0 & 14.2 & 15.4 & 16.7 & 18.0 & 19.4 & 20.9 & -0.4695 & 16.3 & 0.0801 & 13.0 & 14.0 & 15.1 & 16.3 & 17.7 & 19.3 & 21.1 \\
\hline 20 & 0.4581 & 16.6 & 0.0783 & 12.9 & 14.1 & 15.3 & 16.6 & 17.9 & 19.3 & 20.7 & -0.4862 & 16.2 & 0.0797 & 13.0 & 13.9 & 15.0 & 16.2 & 17.6 & 19.2 & 20.9 \\
\hline 21 & 0.4564 & 16.5 & 0.0777 & 12.9 & 14.0 & 15.2 & 16.5 & 17.8 & 19.2 & 20.6 & -0.5024 & 16.2 & 0.0793 & 12.9 & 13.9 & 15.0 & 16.2 & 17.5 & 19.1 & 20.8 \\
\hline 22 & 0.4547 & 16.4 & 0.0772 & 12.8 & 14.0 & 15.2 & 16.4 & 17.7 & 19.0 & 20.4 & -0.5181 & 16.1 & 0.0789 & 12.9 & 13.8 & 14.9 & 16.1 & 17.4 & 19.0 & 20.7 \\
\hline 23 & 0.4531 & 16.3 & 0.0766 & 12.8 & 13.9 & 15.1 & 16.3 & 17.6 & 18.9 & 20.3 & -0.5334 & 16.0 & 0.0786 & 12.8 & 13.8 & 14.8 & 16.0 & 17.4 & 18.9 & 20.6 \\
\hline 24 & 0.4516 & 16.2 & 0.0761 & 12.8 & 13.9 & 15.0 & 16.2 & 17.5 & 18.8 & 20.2 & -0.5482 & 16.0 & 0.0782 & 12.8 & 13.7 & 14.8 & 16.0 & 17.3 & 18.8 & 20.5 \\
\hline
\end{tabular}

references (collected 10-years ago in late 2005), the median values of length-, weight-, and BMI-for-age reported here were all higher across the ages from 0 to 2 years, and also for median head circumference-for-age except for boys in our study compared to the 2005 references for China. The weight-for-length in our study was also slightly higher at most times in both boys and girls. The magnitude of differences between the WHO standards and the current large cohort (assessed in 2015) was larger than the magnitude of differences previously reported compared to the outdated 2005 references for China. Our report provides improved references for evaluating growth of children aged $0-24$ months in modern China.

The height- and weight-for-age values were higher in our longitudinal cohort assessed in five cities of China (Shanghai, Ma'anshan Anhui, Wuhan, Jiangsu, and Guangzhou) than in the cohort based on a cross-sectional study in nine cities of China (Beijing, Shanghai, Harbin, Xian, Nanjing, Wuhan, Guangzhou, Fuzhou, and
Kunming) [3]. This could be a secular trend. The CBCC cohorts recruited pregnant women in provincial or large tertiary maternity and child hospitals. Most mothers had high education (college or higher), maternal smoking was rare, and the living standard were relatively high. Thus, the growth data in this study may reflect infant growth patterns under near-optimal circumstances. Since our data were acquired recently (10 years since 2005), the higher length and weight may also reflect an ongoing secular trend [4]. The WHO data suggest that secular trend may depend on where the cohort was acquired: the predicted adult height from the child's length at 2 years suggested there would be no parent-offspring difference in Norway and the United States (i.e., no increase due to a secular trend), but the predicted adult height was much larger than mid-parental height for the other four countries (Brazil, Ghana, India and Oman). [15] Based on the taller height reported here for ages 0 to 24 months than the 2005 China data, we expect a secular trend (i.e., we predict that average adulthood the height of the children in China 


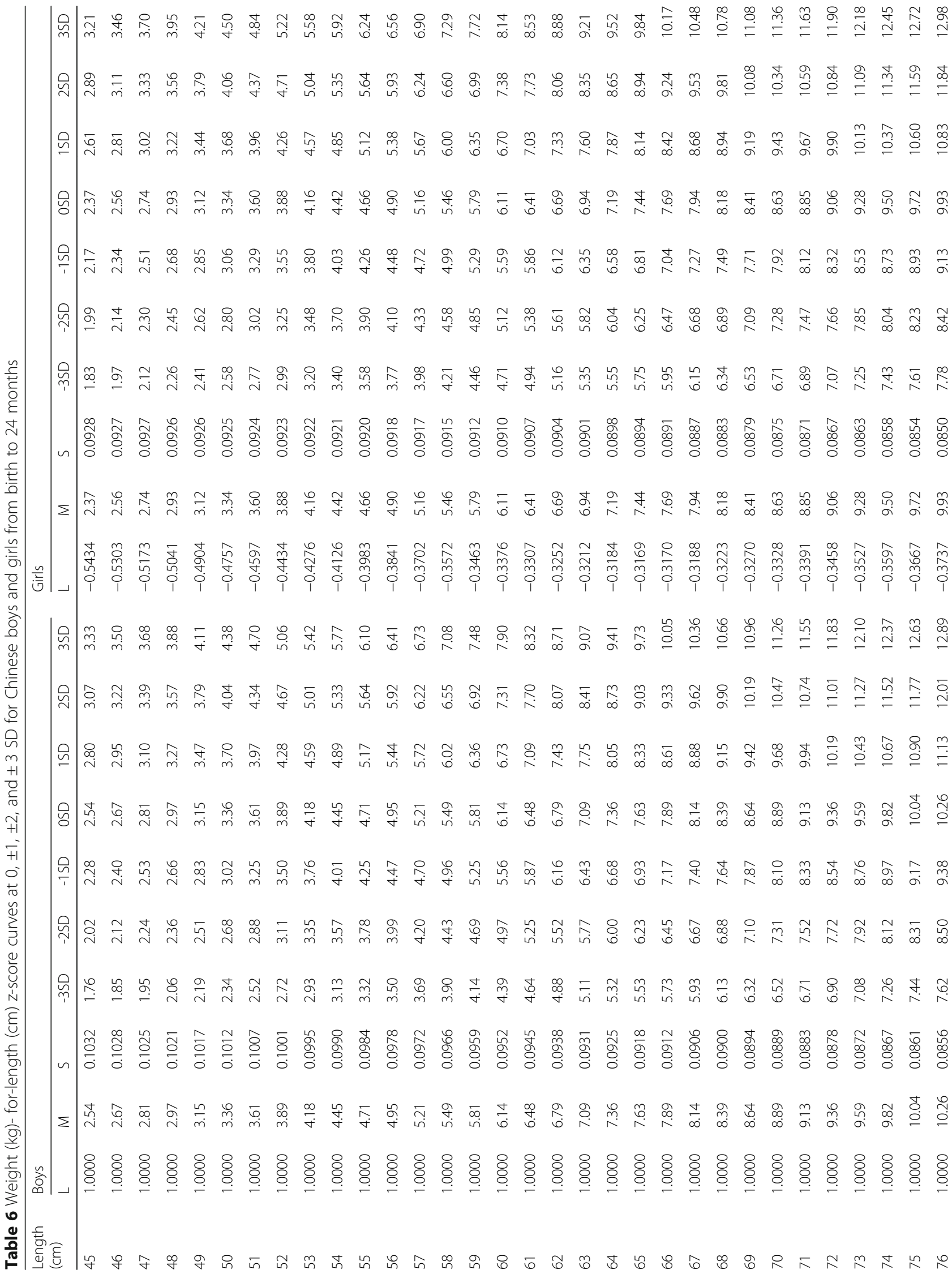




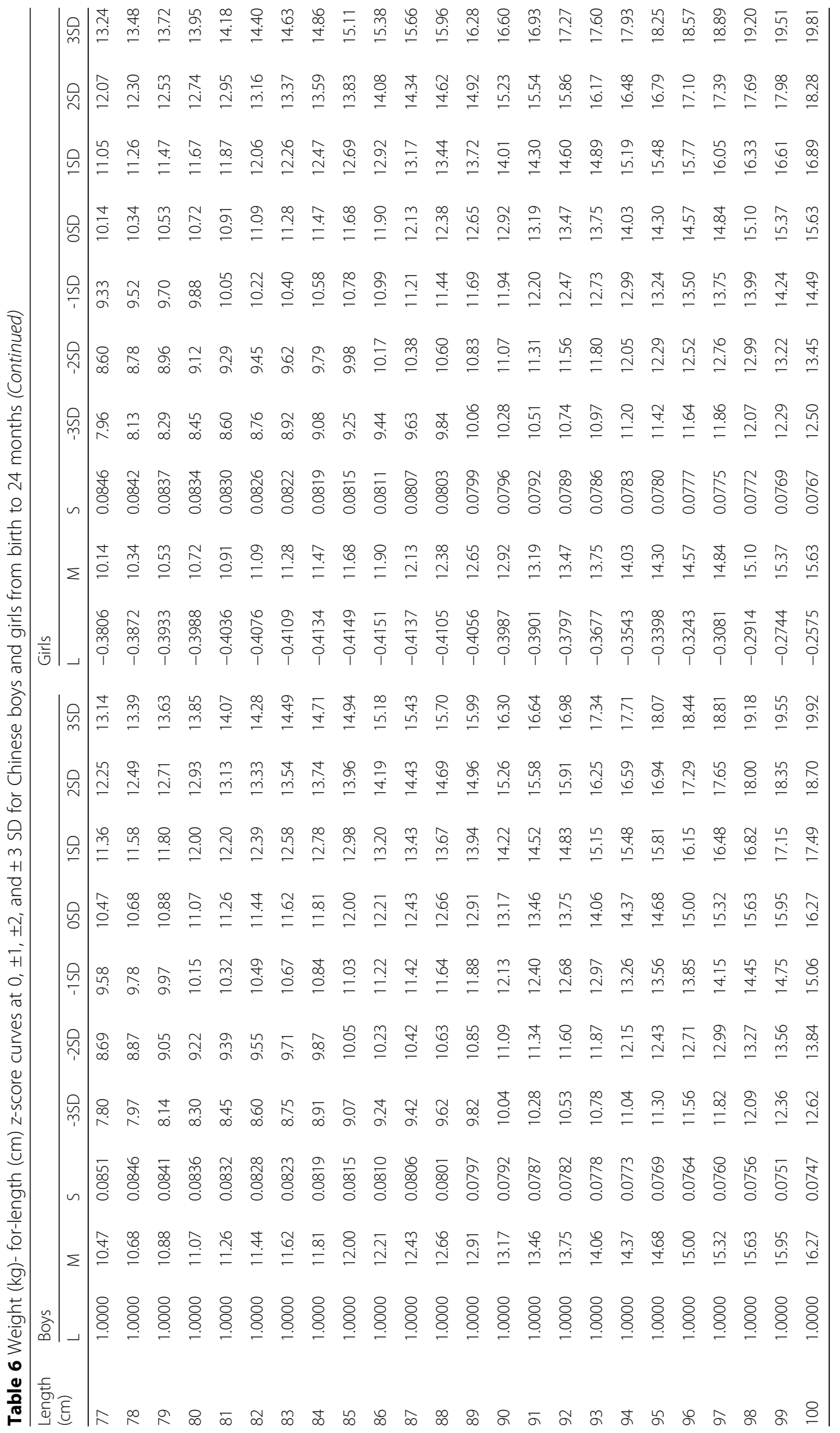




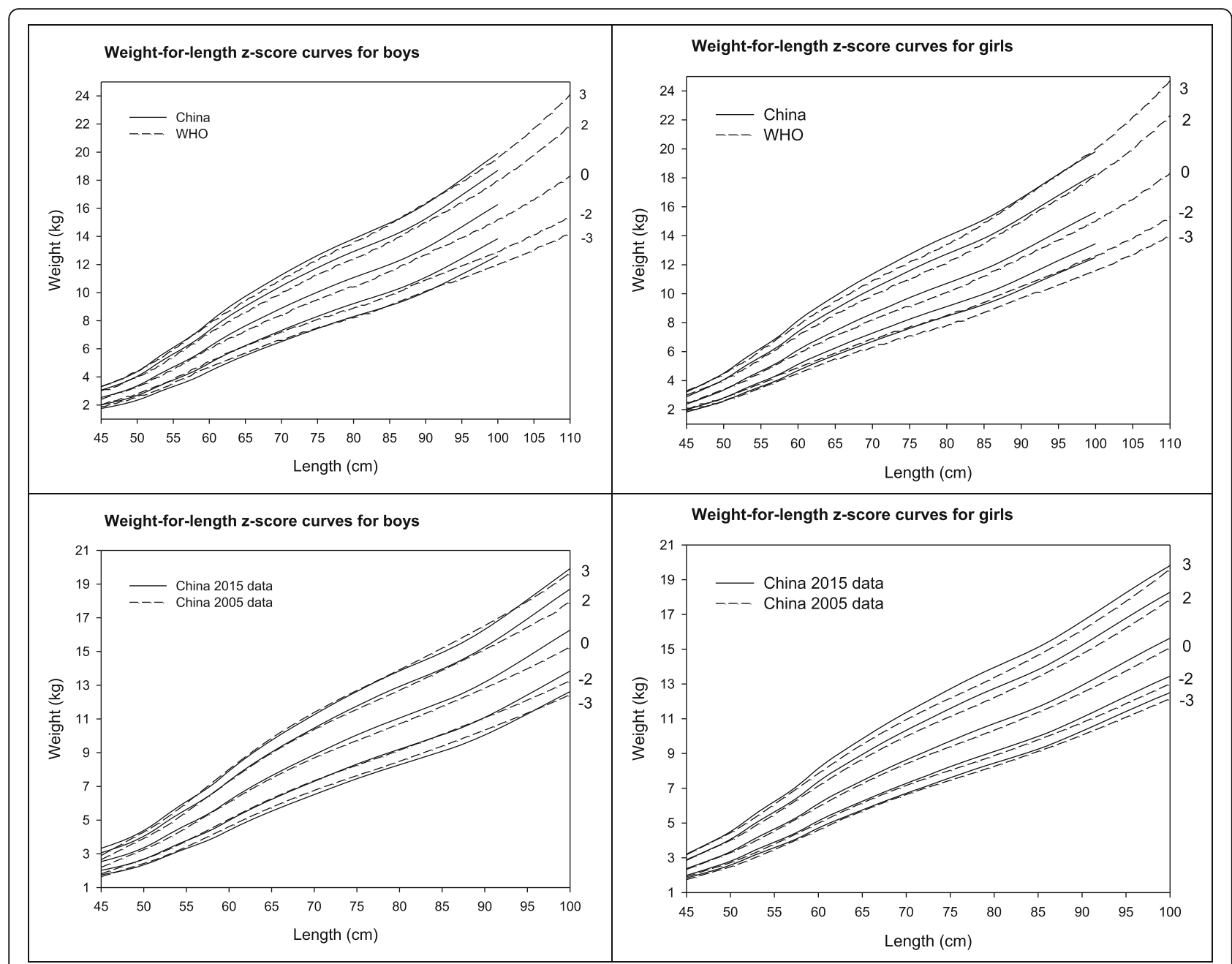

Fig. 3 Comparison of weight-for-length z-score curves from China 2015 data with the WHO standards and Chinese references from 2005 data in boys and girls

will exceed the average height of their parents). While China has undergone dramatic progress in economic and social development, the differences still exist between urban and rural areas, different ethnics, and different social economic. The growth pattern observed in this study may reflect infant growth patterns under more optimal circumstances.

Some studies have found that some child population might have their own growth pattern [16], and our study confirmed that Chinese children may be one of them $[3,17,18]$. The difference in values for height-, weight- and BMI-for-age, weight-for-length, and head circumference in this report in comparison to the WHO standards suggests an interesting country difference, and adds to previous comparison that have been summarized in a recent review [19]. Based on studies from both longitudinal and cross-sectional designs, this review concluded that the WHO standards for height and weight "... endorsed slenderness in the midst of an obesity epidemic" and for head circumference were underestimates (and "... would put many children at risk for misdiagnosis of macrocephaly and microcephaly"). Healthy children in some countries are classified (perhaps inappropriately) as "stunted" [16]. In opposite of findings from some countries (overestimating stunting) [16], overall, our study confirmed that the values of growth measures were higher for the key z-score cutoffs in Chinese children in comparison with WHO growth standards $[3,5]$.

Our references provide the potential cutoffs for evaluating child growth in a population (like in modern China), where children are the center of attention in the family and are growing under favorable environments. Length has been widely used in early detection of stunting, while weight is commonly used as a measure responsive to short-term influences [20]. Head circumference is then the next most-used measure in clinical settings. To reflect the growth centile (position) of a Chinese child in local 
population, conditioned on age and sex, the Chinese growth standards need to be considered. It may help identify the infants who suffer from poor and modifiable conditions, and thus target those who may benefit most from intervention. In this study, while another term was considered ("growth pattern"), the term "growth reference" was used to maintain consistency with the term used in other publications about Chinese cohorts and to contrast to the term "growth standard" used for the WHO cohort.

One characteristic of this study (the large-scale multicenter prospective birth cohort design) allows us to obtain data on pre- and perinatal risk factors including GDM, chronic hypertension, pre-eclampsia and preterm status. Based on this strength, we could exclude affected mother-infant pairs cases at risk for abnormal patterns of child growth. In this study, the difference of mean paternal age among the three groups of children (mothers with GDM, born preterm, and healthy children) is interesting. Older fathers have more de novo mutations in DNA, and this probably contributes to growth in some cases [21]. Another strength of this study is the longitudinal rather than cross-sectional design. Additional longitudinal analysis [22, 23] of these longitudinal data could better capture and describe the tempo of growth, but due to space limitations will be presented elsewhere. Also, in this sample the educational level of mothers was high, and few of the mothers smoked, so the children lived in advantaged condition, and approach the criteria used for establishing the WHO standards (reflecting how children should grow). Therefore, the data here may reflect growth in near-optimal conditions in China, and provide a growth pattern for contemporary Chinese children.

On the other hand, one limitation of this study is that in some cases head circumference at birth was not measured, and some of children were just followed up to 12 months, which reduced the sample size for this measurement. However, our sample size is still larger than the sample sizes in similar longitudinal birth cohort studies conducted in other countries. We have also performed sensitivity analysis to summary the 3rd, 10th, 50th, 90th and 97th percentiles of all growth measures in infant who had all observations up to 24 months (i.e., without missing observations) and the results were similar to those from all observations (data not shown). Thus, the missing data should be "at random" [9] Also, the birth measures obtained from medical records may not be ideal despite of the high number of the participating hospitals (which were all provincial or large tertiary maternity and child hospitals). Thirdly, this was a convenience sample without specific entry criteria as in the WHO study.

\section{Conclusions}

The growth curves in this study represent the growth pattern of today's normal Chinese children, and may provide references for evaluation of the individual growth status of children growing up in modern China.

\section{Additional file}

\begin{abstract}
Additional file 1 Table S1. The overall information of 6 prospective birth cohorts in China for description of growth pattern in this study. Table S2. the numbers of longitudinal anthropometric measurements used for generating growth curves from 2174 infant boys and 2077 infant girls. Table S3. the numbers of longitudinal measures used for generating weight-for-length curves from 2174 infant boys and 2077 infant girls. Table S4. The 3rd, 10th, 50th, 90th and 97th percentiles of growth measures by age among 2174 healthy infant boys. Table S5. The 3rd, 10th, 50th, 90th and 97th percentiles of growth measures by age among 2077 healthy infant girls. Table S6. The difference in the 3rd, 10th, 50th, 90th and 97th percentiles for growth measures between the raw data of 2174 healthy infant boys and the corresponding WHO standards. Table S7. The difference between the 3rd, 10th, 50th, 90th and 97th percentiles for growth measures of the raw data in 2077 healthy infant girls and the corresponding WHO standards by age. Table S8. Distribution of weight by length among 2174 infant boys and 2077 infant girls. Table S9. The difference between the percentile values of the raw data of among 2174 infant boys and 2077 infant girls and the corresponding WHO standards. (DOC $485 \mathrm{~kb}$ )
\end{abstract}

\section{Abbreviations}

ART: Assisted reproductive technologies; CBCC: China Birth Cohort Consortium; GDM: Gestational diabetes mellitus; IADPSG: International Association of Diabetes and Pregnancy Study Groups; MGRS: Multicenter Growth Reference Study; WHO: World Health Organization

\section{Acknowledgements}

We thank Dr. James Swanson, Dr. Michael Hermanussen and Dr. ZhongCheng Luo for their intensive reviews and insightful comments on this manuscript.

\section{Funding}

This work was funded by the Gates Foundation Healthy Birth, Growth \& Development knowledge integration (HBGDki) project (No. OPP1153191). Dr. F. Ouyang was also supported by grants from National Natural Science Foundation of China (grant numbers 81673178; 81372954) and Coordinated Research Project E43032 from International Atomic Energy Agency (IAEA). The funders were not involved in the study design, data collection, analysis, and interpretation, or manuscript preparation.

\section{Availability of data and materials}

This study is based on six birth cohorts. The datasets generated and/or analysed during the current study are not publicly available due to that some of the cohort studies are still ongoing but are available from the corresponding author on reasonable request.

\section{Authors' contributions}

FO conceptualized, designed and conducted this study, performed the statistical analysis, and drafted the manuscript. JZ conceptualized this study, and critically reviewed the manuscript. All authors (JZ, FO, FJ, FT, SX, YX, and $\mathrm{XQ}$ ) took responsibility for one cohort, and critically reviewed the manuscript. All authors read and approved the final manuscript as submitted.

\section{Ethics approval and consent to participate}

This project was approved by the institutional review board (IRB) of Xinhua Hospital affiliated to Shanghai Jiao Tong University School of Medicine (Approval number: XHEC-C-2017-060). Written consent to participate was obtained from participants in each cohort study. For this pooled analysis, the need for consent was waived by IRB of Xinhua Hospital.

Consent for publication

Not applicable. 


\section{Competing interests}

The authors declare that they have no competing interests.

\section{Publisher's Note}

Springer Nature remains neutral with regard to jurisdictional claims in published maps and institutional affiliations.

\section{Author details}

'Ministry of Education and Shanghai Key Laboratory of Children's Environmental Health, Xinhua Hospital, Shanghai Jiao Tong University School of Medicine, 1665 Kong Jiang Road, Shanghai 200092, China. ${ }^{2}$ Department of Developmental and Behavioral Pediatrics, Shanghai Pediatric Transitional Institution, Shanghai Children's Medical Center affiliated with Shanghai Jiao Tong University School of Medicine, Shanghai 200127, China. ${ }^{3}$ School of Public Health, Anhui Medical University, Hefei 230032, China. ${ }^{4}$ Key Laboratory of Environment and Health (HUST), Ministry of Education \& Ministry of Environmental Protection, and State Key Laboratory of Environmental Health (Incubation), School of Public Health, Tongji Medical College, Huazhong University of Science and Technology, Wuhan 430074, Hubei, China. ${ }^{5}$ School of Public Health, Nanjing Medical University, Nanjing 211166, China. ${ }^{6}$ Division of Birth Cohort Study, Guangzhou Women and Children's Medical Center, Guangzhou Medical University, Guangzhou 510000, China.

Received: 1 May 2018 Accepted: 25 October 2018

Published online: 05 November 2018

\section{References}

1. Blake-Lamb TL, Locks LM, Perkins ME, Woo Baidal JA, Cheng ER, Taveras EM. Interventions for childhood obesity in the first 1,000 days a systematic review. Am J Prev Med. 2016;50(6):780-9.

2. de Onis M, Onyango A, Borghi E, Siyam A, Blossner M, Lutter C, Group WHOMGRS. Worldwide implementation of the WHO child growth standards. Public Health Nutr. 2012;15(9):1603-10.

3. Zong XN, Li H. Construction of a new growth references for China based on urban Chinese children: comparison with the WHO growth standards. PLoS One. 2013;8(3):e59569.

4. Cole TJ. The secular trend in human physical growth: a biological view. Econ Hum Biol. 2003;1 (2):161-8.

5. Huang X, Chang J, Feng W, Xu Y, Xu T, Tang H, Wang H, Pan X. Development of a new growth standard for breastfed Chinese infants: what is the difference from the WHO growth standards? PLoS One. 2016;11(12):e0167816.

6. Tanner JM, Whitehouse RH, Takaishi M. Standards from birth to maturity for height, weight, height velocity, and weight velocity: British children, 1965. II. Arch Dis Child. 1966;41(220):613-35.

7. Xu F, Qiu L, Binns CW, Liu X. Breastfeeding in China: a review. Int Breastfeed J. 2009:4:6.

8. American Diabetes A. Diagnosis and classification of diabetes mellitus. Diabetes Care. 2013;36(Suppl 1):567-74.

9. Croy $C D$, Novins DK. Methods for addressing missing data in psychiatric and developmental research. J Am Acad Child Adolesc Psychiatry. 2005;44(12):1230-40.

10. Gillman MW, Rifas-Shiman S, Berkey CS, Field AE, Colditz GA. Maternal gestational diabetes, birth weight, and adolescent obesity. Pediatrics. 2003; 111(3):e221-6.

11. Paauw ND, van Rijn BB, Lely AT, Joles JA. Pregnancy as a critical window for blood pressure regulation in mother and child: programming and reprogramming. Acta Physiol (Oxf). 2016.

12. Ogland B, Vatten $L$, Romundstad PR, Nilsen ST, Forman MR. Pubertal anthropometry in sons and daughters of women with preeclamptic or normotensive pregnancies. Arch Dis Child. 2009;94(11):855-9.

13. Cole TJ, Green PJ. Smoothing reference centile curves: the LMS method and penalized likelihood. Stat Med. 1992;11(10):1305-19.

14. Borghi E, de Onis M, Garza C, Van den Broeck J, Frongillo EA, GrummerStrawn L, Van Buuren S, Pan H, Molinari L, Martorell R, et al. Construction of the World Health Organization child growth standards: selection of methods for attained growth curves. Stat Med. 2006;25(2):247-65.

15. Garza C, Borghi E, Onyango AW, de Onis M, Group WHOMGRS. Parental height and child growth from birth to 2 years in the WHO multicentre growth reference study. Matern Child Nutr. 2013;9(Suppl 2):58-68.

16. Aman B, Pulungan MJ, Batubara JRL, Hermanussen M. Indonesian national synthetic growth charts. Acta Scientific Paediatrics. 2018;1 (1):15.
17. Dang S, Yan H, Wang D. Implication of World Health Organization growth standards on estimation of malnutrition in young Chinese children: two examples from rural western China and the Tibet region. J Child Health Care. 2014;18(4):358-68.

18. Hui LL, Schooling CM, Cowling BJ, Leung SS, Lam TH, Leung GM. Are universal standards for optimal infant growth appropriate? Evidence from a Hong Kong Chinese birth cohort. Arch Dis Child. 2008;93(7):561-5.

19. Natale V, Rajagopalan A. Worldwide variation in human growth and the World Health Organization growth standards: a systematic review. BMJ Open. 2014;4(1):e003735.

20. Tanner JM, Whitehouse RH, Takaishi M. Standards from birth to maturity for height, weight, height velocity, and weight velocity: British children, 1965. I. Arch Dis Child. 1966;41(219):454-71.

21. Acuna-Hidalgo R, Veltman JA, Hoischen A. New insights into the generation and role of de novo mutations in health and disease. Genome Biol. 2016;17(1):241.

22. Tanner JM, Whitehouse RH. Clinical longitudinal standards for height, weight, height velocity, weight velocity, and stages of puberty. Arch Dis Child. 1976;51(3):170-9.

23. Wachholder A, Hauspie RC. Clinical standards for growth in height of Belgian boys and girls, aged 2 to 18. International Journal of Anthropology. 1986; 1(4):327-38.

\section{Ready to submit your research? Choose BMC and benefit from:}

- fast, convenient online submission

- thorough peer review by experienced researchers in your field

- rapid publication on acceptance

- support for research data, including large and complex data types

- gold Open Access which fosters wider collaboration and increased citations

- maximum visibility for your research: over $100 \mathrm{M}$ website views per year

At BMC, research is always in progress.

Learn more biomedcentral.com/submissions 